\title{
Quantitative Method for Determination of Peroxidase in Milk ${ }^{1}$
}

By Frank E. Rice ${ }^{2}$ and Torataro Hanzawa ${ }^{3}$

Department of Chemistry, Corneli University, Ithaca, New York

A

SATISFACTORY method for the quantitative determination of peroxidase in milk is described in this paper. It should find application in determining if milk has been heated to a temperature much above the usual pasteurizing temperature. If reconstituted powdered or evaporated milk or if boiled milk has been adderl to raw milk, application of this method will give proof of the fact, whereas qualitative tests for peroxidase will give no indication.

No method for making quantitative comparisons of peroxidase activity is found in the literature, although practically all other enzymes of milk are estimated quantitatively. Many qualitative tests for peroxidase have been suggested. In all of these, hydrogen peroxide is present, together with some reagent which undergoes a change in color when oxidized, such as guaiacol, paraphenylenediamine, benzidine, pyramidone, ortol, and other photographic developers. The peroxidase is believed to act as a carrier of oxygen from the hydrogen peroxide to the dye. Attempts to modify some of the qualitative tests so that quantitative interpretations could be made were not entirely successful. It was possible to compare the peroxidase activity of different samples only in a general way.

Bach and Chodat ${ }^{4}$ have suggested a method for quantitatively determining peroxidase in extracts from plant tissue, involving the oxidation of soluble pyrogallol to insoluble purpurogallin. When an excess of hydrogen peroxide and pyrogallol is present, the extent to which the reaction takes place depends upon the amount of the peroxidase, all other conditions such as time and temperature being the same. The weight of the final product is taken as a measure of the peroxidase activity.

The reaction is probably as follows:

$$
\underset{\text { pyrogallol }}{3 \mathrm{C}_{6} \mathrm{H}_{3}(\mathrm{OH})_{3}}+2 \mathrm{O}=\mathrm{C}_{6} \mathrm{H}_{3}(\mathrm{OH}) \underset{\text { purpurogallin }}{\left(\mathrm{OOC}_{6} \mathrm{H}_{3}(\mathrm{OH})_{2}\right)_{2}}+2 \mathrm{H}_{2} \mathrm{O}
$$

\section{Application of Bach and Chodat Method to Milk SAMPLES}

Ten cc. of milk were diluted with $50 \mathrm{cc}$. of water, and treated with $20 \mathrm{cc}$, of 5 per cent pyrogallol and $10 \mathrm{cc}$. of 1 per cent hydrogen peroxide. The mixture was stirred well, allowed to stand several days at room temperature $\left(19^{\circ}\right.$ to $21^{\circ}$ ), and filtered on a dried and weighed filter. The precipitate was first washed with a freshly prepared mixture similar in composition to the precipitating solution, made by adding to $50 \mathrm{cc}$. of distilled water $20 \mathrm{cc}$. of 5 per cent pyrogallol and $10 \mathrm{cc}$. of 1 per cent hydrogen peroxide. It was finally washed with $100 \mathrm{cc}$. of distilled water and dried to constant weight at the temperature of boiling water.

TIME NECESSARY FOR COMPLETING THE REACTION-Although Bach and Chodat found that 24 hrs. was sufficient time to complete the reaction with plant juice extracts, with milk much longer time is necessary before the reaction has reached an equilibrium. Seven days is a satisfactory reaction time.

2. Presented before the Division of Biological Chemistry at the 62nd Meeting of the American Chemical Society, New York, N. Y., September 6 to 10,1921 .

Assistant Professor of Agricultural Chemistry, Cornell University.

3 Professor of Chemistry, Agricultural College of Japan.

Ber., 37 (1904), 1342.

H. Wichelhaus, Ibid, 5 (1872), 846 .
Expt. I-Several identical mixtures were started on the same sample of milk. Each day one was filtered and weighed. In all cases $10 \mathrm{cc}$. of milk were used, and the weights of purpurogallin in Table I are given in $\mathrm{mg}$. per $10 \mathrm{cc}$. of milk.

\begin{tabular}{|c|c|c|}
\hline \multicolumn{3}{|c|}{ TABLE I } \\
\hline $\begin{array}{l}\text { Raw } \\
\text { Skim Milk }\end{array}$ & $\begin{array}{l}\text { Pasteurized } \\
\text { Skim Milk }\end{array}$ & $\begin{array}{c}\text { Boiled } \\
\text { Skim Milk }\end{array}$ \\
\hline 14.6 & 10.4 & $\ldots$ \\
\hline 25.4 & 19.8 & \\
\hline 28.0 & 21.4 & 0 \\
\hline $\begin{array}{l}30.5 \\
31.2\end{array}$ & $\begin{array}{l}26.8 \\
27.0\end{array}$ & Trace \\
\hline 31.8 & $\begin{array}{l}28.0 \\
28.0\end{array}$ & $\ldots$ \\
\hline 31.5 & 28.2 & 8.2 \\
\hline 32.0 & 29.0 & $\ldots \ldots$ \\
\hline
\end{tabular}

Time of Reaction
Days
1
2
3
4
5
6
7
8

EFFECT OF PRESENCE OF ATR-In the sample containing boiled skim milk (Table I) it is seen that some purpurogallin precipitated out in 7 days. The precipitation took place at the surface of the liquid and since the determinations were run in beakers, it was believed that the air had influenced the reaction. Certainly there should be no peroxidase in boiled milk.

The following observations were made: A solution containing boiled milk together with pyrogallol alone, or with hydrogen peroxide, and in presence of air precipitated purpurogallin after about 5 days. A mixture of boiled milk, pyrogallol, and hydrogen peroxide, covered with paraffin or filled into a bottle so that air was excluded, never precipitated purpurogallin. From this it is evident that it is necessary to prevent the access of air to the reacting mixture; otherwise all the purpurogallin precipitated could not be attributed to the action of peroxidase.

To avoid this difficulty, glass-stoppered bottles of 100to 130-cc. capacity were employed. After the measured amounts of milk, water, hydrogen peroxide, and pyrogallol - had been mixed, the bottles were entirely filled with a solution of hydrogen peroxide and pyrogallol of composition similar to that which was already in the mixture, and tightly stoppered.

REMOVAL OF FAT FROM RESIDUE-Since any fat in the milk would probably remain on the filter, it was desirable to wash the precipitate with a fat solvent. Ethyl ether readily dissolves purpurogallin, but petroleum ether does not.

Expt. 2-Two of the purpurogallin residues from skim milk were washed five times with petroleum ether, and after each washing the filter was dried and weighed.

$\begin{array}{lcc} & \text { REsIDUE A } & \text { REsIDUE B } \\ \text { Mg. } & \text { Mg. } \\ \text { Precipitate } & 36.0 & 31.8 \\ \text { After 1st washing } & 30.8 & 27.0 \\ \text { After 2nd washing } & 30.4 & 26.8 \\ \text { After 3rd washing } & 30.2 & 27.0 \\ \text { After 4th washing } & 30.4 & \mathbf{2 7} .0 \\ \text { After 5th washing } & 30.4 & \mathbf{2 7 . 0}\end{array}$

These results showed that in applying the method to milk it was necessary to wash the residue finally to remove the fat. In all subsequent determinations after the last washing with water the filters were dried and washed twice with petroleum ether before finally drying and weighing.

PROPORTIONS OF HYDROGEN PEROXIDE AND OF PYROGALLOL -In order that the enzyme may have opportunity to exert its full effect, it is important that hydrogen peroxide and pyrogallol be present in excess. In the two following experiments the effect of varying these constituents was determined: 
Expt. 3-In each mixture the hydrogen peroxide was varied, while the other ingredients were kept constant.

$\begin{array}{cccccc}\begin{array}{c}\text { 1.Per cent } \\ \text { Hydrogen } \\ \text { Cc. }\end{array} & \begin{array}{c}\text { Hydrogen } \\ \text { Peroxide } \\ \text { Per cent }\end{array} & \begin{array}{c}\text { Water } \\ \text { Added } \\ \text { Cc. }\end{array} & \begin{array}{c}5 \text { Per cent } \\ \text { Pyrogallol } \\ \text { Cc. }\end{array} & \begin{array}{c}\text { Skim } \\ \text { Milk }\end{array} & \begin{array}{c}\text { Purpurogallin } \\ \text { in Days } \\ \text { Mg. }\end{array} \\ 2 & 0.025 & 58 & 10 & 10 & 22.4 \\ 4 & 0.050 & 56 & 10 & 10 & 27.4 \\ 6 & 0.075 & 54 & 10 & 10 & 27.6 \\ 8 & 0.100 & 52 & 10 & 10 & 27.2 \\ 10 & 0.125 & 50 & 10 & 10 & 27.4 \\ 12 & 0.150 & 48 & 10 & 10 & 28.2 \\ 14 & 0.175 & 46 & 10 & 10 & 27.6 \\ 16 & 0.200 & 44 & 10 & 10 & 28.0 \\ 18 & 0.225 & 42 & 10 & 10 & 27.4 \\ 20 & 0.250 & 40 & 10 & 10 & 28.4\end{array}$

Expt. 4-The proportion of pyrogallol was next varied.

\begin{tabular}{|c|c|c|c|c|c|}
\hline $\begin{array}{l}5 \text { Per cent } \\
\text { Pyrogallol } \\
\text { Cc. }\end{array}$ & $\begin{array}{c}\text { Pyrogallol in } \\
\text { Mixture } \\
\text { Per cent }\end{array}$ & $\begin{array}{l}\text { Water } \\
\text { Added } \\
\text { Cc. }\end{array}$ & $\begin{array}{c}\text { Hydrogen } \\
\text { Peroxide } \\
\text { Cc. }\end{array}$ & $\begin{array}{l}\text { Skim } \\
\text { Milk } \\
\text { Cc. }\end{array}$ & $\begin{array}{c}\text { Purpurogal- } \\
\text { lin in } 7 \text { Days } \\
\text { Mg. }\end{array}$ \\
\hline 2 & 0.125 & 58 & 10 & 10 & 18.8 \\
\hline 4 & 0.250 & 56 & 10 & 10 & 22.6 \\
\hline 6 & 0.375 & 54 & 10 & 10 & 28.4 \\
\hline 8 & 0.500 & $5 \overline{2}$ & 10 & 10 & 31.2 \\
\hline 10 & 0.625 & 50 & 10 & 10 & 31.0 \\
\hline 12 & 0.750 & 48 & 10 & 10 & 31.6 \\
\hline 14 & 0.875 & 46 & 10 & 10 & 31.4 \\
\hline 16 & 1.000 & 44 & 10 & 10 & 31.6 \\
\hline 18 & 1.125 & 42 & 10 & 10 & 30.8 \\
\hline 20 & 1.250 & 40 & 10 & 10 & 31.4 \\
\hline
\end{tabular}

These results show that all proportions of hydrogen peroxide above 0.05 per cent and of pyrogallol above 0.5 per cent are sufficient. In further experiments, therefore, $10 \mathrm{cc}$. of hydrogen peroxide were continued, but the quantity of pyrogallol was reduced to $10 \mathrm{cc}$.

COMPARISON OF WHOLE AND SKIM MILK-A sample of skim milk taken from a cream separator was compared with the whole milk from which it came. Ten cc. of the whole milk yielded $34.2 \mathrm{mg}$. of purpurogallin; with the skim milk there were obtained $32.0 \mathrm{mg}$. In another instance whole milk was placed in a tube, warmed slightly, and centrifuged. Ten cc. of the skim milk layer gave $31.8 \mathrm{mg}$., and an equal volume of the whole milk $33.2 \mathrm{mg}$. purpurogallin.

Exceedingly great difficulty was always found in filtering the mixture containing the whole milk, while the skim milk mixture filtered readily. For this reason it is recommended that before a sample of milk be run by the pyrogallol method it be first centrifuged to remove most of the fat.

\section{Description of Method}

Place sample in a tube, warm slightly, and centrifuge. Transfer $10 \mathrm{cc}$. of the skim milk to a glass-stoppered bottle of about 100-cc. capacity, add 50 cc. of distilled water, followed by $10 \mathrm{cc}$. of 5 per cent pyrogallol and $10 \mathrm{cc}$. of 1 per cent hydrogen peroxide. Shake well, and fill up the bottle with a solution prepared by mixing $60 \mathrm{cc}$. of water with $10 \mathrm{cc}$. of 1 per cent hydrogen peroxide and $10 \mathrm{cc}$. of 5 per cent pyrogallol. Stopper tightly, and let stand for 7 days $^{6}$ at room temperature. Filter on a weighed Gooch, wash the precipitate, first with the pyrogallol-hydrogen peroxide mixture just described, and finally with distilled water. Use no more than the necessary quantity of water in the washing, since purpurogallin is slightly soluble. When the washings do not give a dark blue color with ferric chloride solution, all the pyrogallol has been removed and the filter has been sufficiently washed.

B Other modifications of the method of Bach and Chodat have been offered, stuch as that of Willstätter and Stoll [Ann., $416(1918), 21]$. In general these methods have been adapted to the determination of peroxidase in fractions from plant materials, In these fractions the peroxidase activity is much greater than in milk, and for this reason a considerable amount of purpurogallin is produced in a very short time. Under such conditions the reaction is not allowed to run to completion but is stopped after a short period and the amount of purpurogallin produced during this time is taken as a measure of the amount of peroxidase. In milk, however, the activity of the enzyme is so weak that even by allowing the reaction to go to completion (which requires about 7 days), a relatively small weight of purpurogallin is obtained. On this account the authors consider it wise to allow the full time for the determination; however, it would be possible to obtain comparative results in from 1 to 3 days.
Dry the filter thoroughly, wash two or three times with petroleum ether, dry, and weigh. The weight of purpurogallin (in mg.) yielded by $10 \mathrm{cc}$. of milk is to be called the peroxidase number.

Relation between Amount of Peroxidase in Milu and the Peroxidase Number

In order to show that the relative amounts of peroxidase in milk could be determined by the amount of purpurogallin precipitated, raw and boiled skim milk were mixed in various proportions and run by regular method (Expt. 5):

\section{Raw : Boiled \\ Peroxidase numbers
Ratio \\ $\begin{array}{ccccc}100: 0 & 75: 25 & 50: 50 & 25: 75 & 0: 100 \\ 28.2 & 21.4 & 15.4 & 8.2 & 0\end{array}$ \\ Effect of Pasteurizing and of Preservatives on Peroxidase ACtivity}

In Expt. 1 a comparison may be made of the peroxidase numbers of raw and pasteurized milk. The pasteurization. was brought about by bringing the milk to $145^{\circ} \mathrm{F}$. in $10 \mathrm{~min}$., holding at that temperature for $30 \mathrm{~min}$., and finally cooling. to $60^{\circ} \mathrm{F}$. in $10 \mathrm{~min}$.

Expt.6-In this experiment the peroxidase numbers of portions. of skim milk were determined after different heat treatments. The samples were heated at the various temperatures for $30 \mathrm{~min}$. except for the blank which was untreated; the peroxidase numbers were as follows: blank, $31.8 ; 145^{\circ} \mathrm{F}$., $25.6 ; 155^{\circ} \mathrm{F}, 24.2 ; 165^{\circ} \mathrm{F}$., $0 ; 180^{\circ} \mathrm{F} ., 0$.

Heating at $145^{\circ} \mathrm{F}$, and at $155^{\circ} \mathrm{F}$. is seen to reduce the peroxidase number to some extent, though the critical point is evidently between $155^{\circ}$ and $165^{\circ}$.

A sample of skim milk, $10 \mathrm{cc}$. of which yielded a peroxidase number of 30.2 when fresh, gave 27.6 after being held at $40^{\circ} \mathrm{F}$. for 2 days.

A portion of the same milk was preserved with 1 per cent mercuric chloride, and to another portion was added formaldehyde at the rate of $1 \mathrm{cc}$. to a pint. The sample containing mercuric chloride could not be determined on account of a precipitate, resulting probably from a precipitation of the casein by the mercury. The sample containing formaldehyde gave a peroxidase number of 0 , which is probably due to the reducing effect of the formaldehyde.

Evidently neither mercuric chloride nor formalin can be used to preserve samples of milk in which the peroxidase number is later to be determined.

When milk is held on ice for 2 days the peroxidase activity is seen to fall off to some extent.

\section{Summary}

1-The method proposed by Bach and Chodat for the estimation of peroxidase in plant juices is adapted with modifications for milk.

2-The method depends upon the oxidation of pyrogallol: by hydrogen peroxide, the reaction being catalyzed byperoxidase. The weight of purpurogallin which precipitates out (mg. resulting from the action of $10 \mathrm{cc}$. of milk) is called. the "peroxidase number."

3-Seven days are necessary for the reaction to reach an equilibrium. Since in this length of time air is a factor in the precipitation of purpurogallin, the reaction must takeplace in absence of air.

4-To remove fat the residue is washed with petroleum. ether, in which purpurogallin is insoluble.

5-Whole milk and skim milk are about equal in peroxidase activity.

6 - By mixing raw and boiled milk in varying proportions it was shown that the peroxidase number varies quite regularly with the concentration of peroxidase.

7 -Heating milk below $155^{\circ} \mathrm{F}$. for $30 \mathrm{~min}$. reduces but does not destroy peroxidase activity. Holding on ice for 2 days reduces the action slightly.

8-Samples of milk for peroxidase estimation cannot be: preserved with mercuric chloride or formaldehyde. 